\title{
Role of hybrid tool pin profile on enhancing welding speed and mechanical properties of AA2219- T6 friction stir welds

\author{
P.Mastanaiah ${ }^{1}$, Abhay Sharma ${ }^{2}$, G.Madhusudhan Reddy ${ }^{3}$ \\ ${ }^{1}$ Defence Research and Development Laboratory, Kanchanbagh, Hyderabad, India -500058 \\ ${ }^{2}$ Indian Institute of Technology Hyderabad, Kandi Campus, Sangareddy, India-502285 \\ ${ }^{3}$ Defence Metallurgical Research Laboratory, Kanchanbagh, Hyderabad, India -500058
}

\begin{abstract}
The friction stir welds of thick precipitation-hardenable aluminum alloys suffer from reduced joint strength due to dissolution/coarsening of the strengthening precipitates. The article portray hybrid pin profiled tool that enables sound welds at speeds 7-times faster than a conventional tool (a conical threaded tool), without pin breakage. The conical threaded and triangular cross-section in the upper and lower pin half-lengths of the hybrid tool facilitate material flow in a downward direction and shear deformation at a faster rate, respectively. The paper brings out the process mechanism responsible for the enhanced welding speed and mechanical properties obtainable with the hybrid tool through a case of 13-mm thick aluminum alloy AA2219-T6. The hybrid tool facilitates a $28 \%$ improvement in weld strength by reducing TMAZ softening, as evidenced by the microhardness and mechanical properties and supported by microstructural investigation and fractography.
\end{abstract}

Keywords: Hybrid tool pin; friction stir welding; high thick; AA2219 Al alloy.

\section{Introduction}

Many precipitation hardenable aluminum alloys offer good weldability in fusion welding processes but suffer from problems such as loss of strength in weld metal or the heat affected zone (HAZ), segregation of alloying elements in the fusion zone, and poor weld joint efficiency (Rao et al., 2004). Friction stir welding (FSW) -which welds in the solid state - has been proven to be a successful joining process. Aerospace components, such as cryogenic fuel tanks, airframes, nose cap shells, and composite wrapped high-pressure vessels, are fabricated with high thick $(\geq 7.5 \mathrm{~mm})$ friction stir welded aluminum alloys for which the conventional tool pin profiles often produce results of unacceptable quality (Perrett et al., 2007). High thickness welds have a heterogeneous microstructure because of temperature and deformation gradients (Avettand et al., 2015). Alternative means to control thermal gradient, such as the use of backing plates with varied thermal diffusivities, have been shown to have a positive impact on mechanical properties (Upadhyay and Reynolds, 2013). The joint efficiency of precipitation-strengthened alloy 
friction stir welds can be improved either by reduction or extraction of heat from the HAZ and thermomechanically affected zone (TMAZ) as quickly as possible (De and Mishra, 2011). For example, an increase in tensile strength and a decrease in elongation are observed in underwater friction stir welds (Huijie et al., 2010). The reduction of heat by an increase in welding speed causes reduced precipitate coarsening in the HAZ, thus leading to a moderately increased joint strength with the fracture location shifting towards the TMAZ from the HAZ, as reported by Zhang et al. (2011) and Liu et al. (2011 a). Increasing the welding speed beyond $200 \mathrm{~mm} / \mathrm{min}$ might result in a top groove defect because of the difference between the material flow speed and the tool travel speed ( $\mathrm{Li}$ and Liu, 2013).

Most research on friction stir welding of precipitation-hardenable aluminum alloys has focused on relatively smaller thicknesses, ranging from 2.5 to $7.5 \mathrm{~mm}$. To reduce HAZ softening, it is difficult to use alternative methods, such as underwater FSW, in industrial applications because of the large size of the airframe structures, the complex tooling and welding fixtures. Thus, there exists a strong urge to establish a method to reduce HAZ softening thereby increasing joint strength of these aluminum alloy friction stir welds by welding at maximum possible travel speeds, which also increases the industrial production rate. Because the tool pin tends to break at higher speeds, welding at faster travel speed remains a concern in FSW of aluminum alloys. It is therefore necessary to understand the influence of tool pin profile and FSW process parameters on TMAZ/HAZ softening in order to find ways to deal with these issues. A specially designed FSW tool is envisaged that could improve the material flow in the stirred zone and allow welding at very high travel speeds, without the formation of groove or void defects, specifically in case of high thick aluminum alloy plates. Here, such a hybrid tool is investigated for its capability to produce a sound weld at very high travel speeds compared to a conventional conical threaded tool. The findings were also corroborated by an investigation of the microstructure and mechanical properties using optical, destructive, and non-destructive methods.

\section{Experimental work}

Aluminum alloy AA2219-T6 rolled plates $(300 \times 100 \times 13 \mathrm{~mm})$ were friction stir welded in a single pass, normal to the rolling direction, with a square butt joint configuration. The chemical composition and mechanical properties of the parent metal are presented in Table1. The tool material was hot worked tool steel (AISI H13) heat-treated to a hardness of $50 \mathrm{HRc}$ with a chemical composition of C-04, Cr-0.25, Mn-

0.4, Mo-1.35, Si-1, V-1, and Fe-balance (all elements in \% wt.). Two types of tools were employed; a conventional tool pin with tapered cylindrical threaded configuration (larger and smaller diameters 10 and $6 \mathrm{~mm}$, respectively) and a specially designed hybrid FSW tool with conical threaded and triangular cross- 
sections (Figure 1). The shoulder diameter was maintained constant $(27 \mathrm{~mm})$ for both tools, thereby ensuring that the pin profile is the only major variation between the tools.

Table 1. Chemical composition and mechanical properties of base material.

\begin{tabular}{|c|c|c|c|c|c|c|c|c|c|c|}
\hline \multirow{2}{*}{ Base Material } & \multicolumn{5}{|c|}{ Chemical composition } & \multicolumn{3}{c|}{ Tensile properties } & Hardness \\
\cline { 2 - 9 } & $\% \mathrm{Cu}$ & $\% \mathrm{Si}$ & $\% \mathrm{~V}$ & $\% \mathrm{Zn}$ & $\% \mathrm{Ti}$ & $\% \mathrm{Fe}$ & UTS (MPa) & $0.2 \% \mathrm{YS}(\mathrm{MPa})$ & $\% \mathrm{El}$. & $(\mathrm{Hv})$ \\
\hline AA2219-T6 & 5.83 & 0.03 & 0.08 & 0.054 & 0.04 & 0.1 & 443 & 338 & 10 & 139 \\
\hline
\end{tabular}

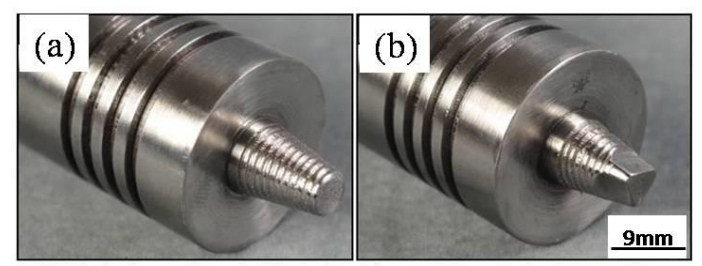

Figure 1. FSW Tool pin profiles (a) Conical threaded (b) Hybrid

The thermal cycles were recorded during the welding. Schematic drawings showing the experimental setup and positioning of the thermocouples are shown in Figure $2 \mathrm{a}$ and $2 \mathrm{~b}$, respectively. The thermocouples were positioned approximately $1 \mathrm{~mm}$ away from the TMAZ on both the advancing and retreating sides of the weld joint. During the pilot experiments, the tools were tested at different welding speeds. The conventional tool pin was broken (shown in Figure 3) while welding with a travel speed of $60 \mathrm{~mm} / \mathrm{min}$ and tool rotation speed of 500rpm. Tool breakage was considered whenever the tool pin was broken during the welding at any location along the joint line. A broken tool pin can be noticed as a white spot in X-ray radiographs (Figure 3b). The hybrid tool was employed to weld with travel speeds starting from $40 \mathrm{~mm} / \mathrm{min}$ at an interval of $60 \mathrm{~mm} / \mathrm{min}$. The tool pin was broken at a $340 \mathrm{~mm} / \mathrm{min}$ travel speed (shown as a white spot in the radiograph of Figure 4b). Three of each tool type were tested. Images of the FSW tools after tool pin breakage are shown in Figures $3 \mathrm{c}$ and $4 \mathrm{c}$.
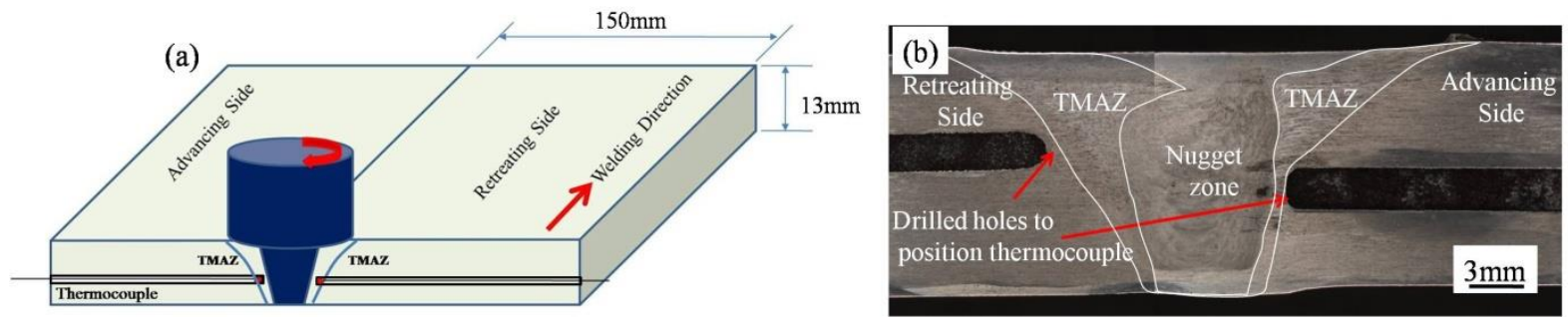

Figure 2. (a) A schematic sketch of welding experimental setup (b) Macrostructure of weld joint cross section depicting pre-drilled holes for positioning thermocouples close to TMAZ. 


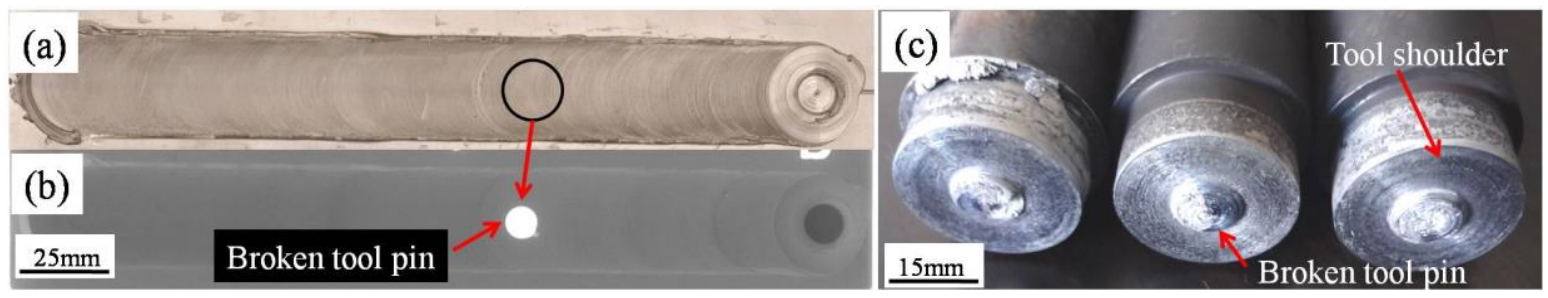

Figure 3. (a) Top appearance (b) X-ray radiograph of FSW joint made by conical threaded tool at a travel speed of $60 \mathrm{~mm} / \mathrm{min}$ (c) conical threaded tools after pin breakage

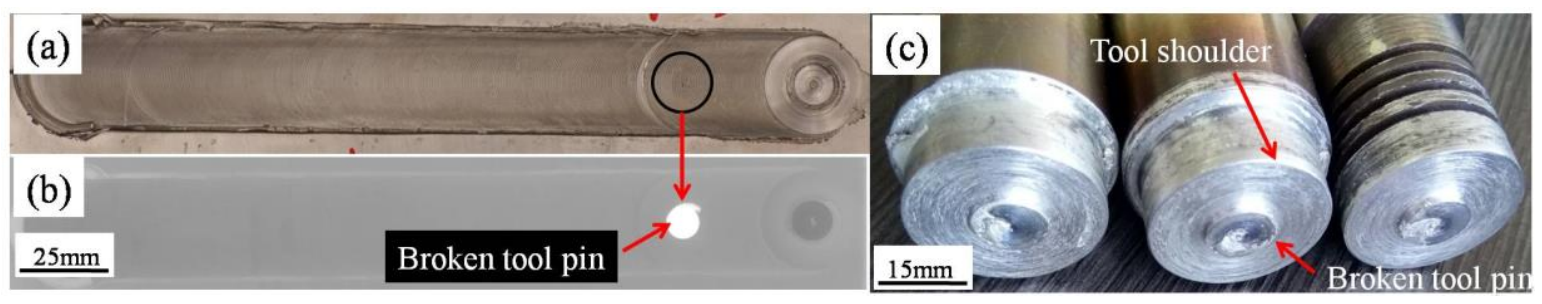

Figure 4. (a) Top appearance (b) X-ray radiograph of FSW joint made by hybrid tool at a travel speed of $340 \mathrm{~mm} / \mathrm{min}$ (c) hybrid tools after pin breakage

The final experiments were conducted with welding parameters, as given in Table 2. A constant tool rotation speed of 500rpm is maintained all through the experimentation. The weld joints were visually inspected and further subjected to non-destructive X-ray radiography and dye penetrant tests. The sound FSW joints were sectioned perpendicular to the welding direction for microstructural examination by optical microscopy. The weld macrostructures of the transverse weld cross section were examined under an optical metallurgical microscope after conventional metallographic sample preparation techniques and after etching with Keller's reagent. The composition of intermetallic compounds was analyzed using energy-dispersive spectroscopy (EDS). The electron backscattered diffraction (EBSD) measurements were done using a scanning electron microscope (SEM). The grain size measurements were done using the line intercept method.

Table 2. Friction stir welding parameters used in experimentation

\begin{tabular}{|c|c|c|c|c|}
\hline S.No & FSW tool & Rotation Speed (rpm) & Travel Speed (mm/min) & Observations \\
\hline 1 & \multirow{2}{*}{$\begin{array}{c}\text { Conical } \\
\text { threaded }\end{array}$} & 500 & 40 & Joint quality is good \\
\hline 2 & & 500 & 60 & Tool pin is broken \\
\hline 3 & \multirow{6}{*}{ Hybrid } & 500 & 40 & Joint quality is good \\
\hline 4 & & 500 & 100 & Joint quality is good \\
\hline 5 & & 500 & 160 & Joint quality is good \\
\hline 6 & & 500 & 220 & Joint quality is good \\
\hline 7 & & 500 & 280 & Joint quality is good \\
\hline 8 & & 500 & 340 & Tool pin is broken \\
\hline
\end{tabular}


The microhardness was measured at a 100gf load covering various zones of weldments and base materials across the mid-thickness of the transverse weld cross section at an interval of $0.25 \mathrm{~mm}$. The transverse tensile test was conducted according to the standard ASTM E8. The room temperature tensile properties of three specimens for each experiment were evaluated in the as-welded condition with a crosshead speed of $1 \mathrm{~mm} / \mathrm{min}$. To understand the mode of failure and to test for the presence of any intermetallic compound particles on these fracture surfaces, the fractured surfaces of the tensile test specimens were examined under an SEM at an accelerating voltage of $20 \mathrm{kV}$.

\section{Results and discussion}

\subsection{Temperature profiles during welding}

The temperature versus time plots recorded at a location close to the TMAZ are shown in Figure 5. The two temperature profiles correspond to the weld joints produced using the conical threaded and hybrid tools at travel speeds of 40 and $280 \mathrm{~mm} / \mathrm{min}$, respectively. For the conical threaded tools, the curve slopes during the heating and cooling phases are close to equal because the residence time of the tool increases due to low welding speed. For the weld produced by the hybrid tool, the slope of the curve is steeper during heating than during cooling. Compared to the conventional tool, the hybrid tool produces a higher heating rate and takes a longer time for the dissipation of heat to the adjacent base metal. The peak temperature measured during welding with the conical threaded tool is close to $350^{\circ} \mathrm{C}$, while that of the hybrid tool was $250^{\circ} \mathrm{C}$, which welded at faster travel speeds. Peak temperatures close to these values are reported by Xu et al. $\left(2009^{\mathrm{a}}\right)$. Thermal history affected the microstructures and properties of welds, as will be explained later.

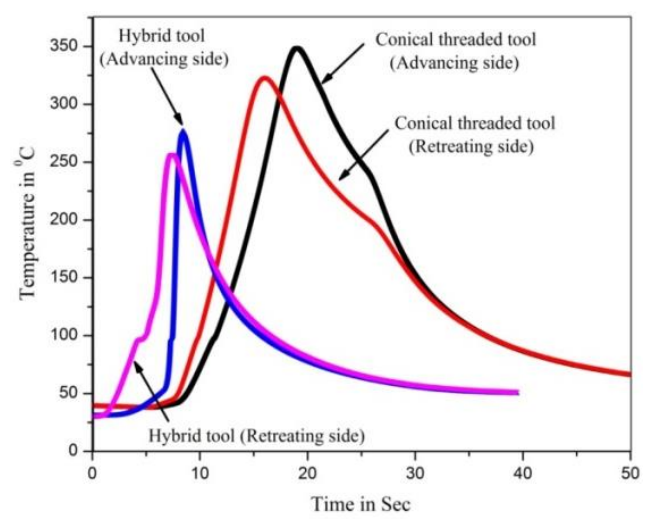

Figure 5. The temperatures versus time plots recorded during welding near TMAZ.

\subsection{Surface appearance and microstructure}

Tool design and weld pitch (i.e., travel speed/ rotation speed) control the surface appearance, material flow, and heat input, and thereby the quality of a friction stir weld joint. Figure 6 shows the appearance 
of the weld joint top surfaces produced using the two tool types under different welding parameters. The top surface of the weld joints looks clean, without any surface defect. The weld produced by the conical threaded tool with lower travel speed, and thus lower weld pitch, has no ripple formation, which could be due to excessive welding heat and stirring of the shoulder on the top surface as it remained for a relatively long time at any location. The joint made by the hybrid tool contains uniformly spaced ripples on the top surface. This is because of the higher travel speed and mechanical shanking effect imparted by the tool shoulder.

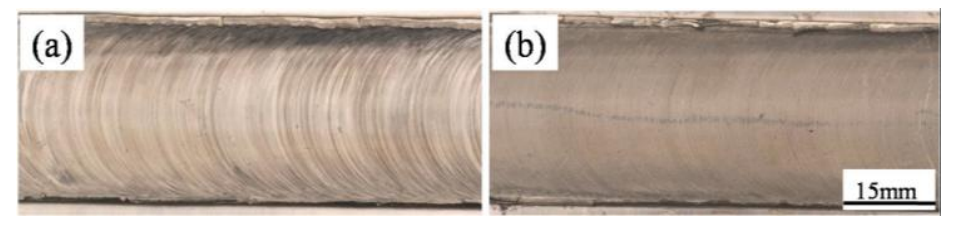

Figure 6. Top weld surfaces - (a) Conical threaded (parameers-500rpm, 40mm/min) (b) hybrid tool (parameters-500rpm, 280mm/min)

The influence of tool pin profile on stirring in the weld nugget can be observed in the macrostructures (Figure 7). The macrostructure of the weld made by the conical threaded tool pin at 500rpm and 40mm/min (Figure 7a) has a pot-like nugget zone (NZ) surrounded by TMAZ spreading through the complete thickness. The width of the TMAZ gradually reduces in thickness from top to bottom. The width of the nugget zone in the weld made by the hybrid tool is smaller than that of the conical threaded tool. When the travel speed was increased using the hybrid tool (Figure 7b-f), a defectfree joint is achieved with a gradually reducing width of nugget zone and a proportionate reduction in the width of the TMAZ.
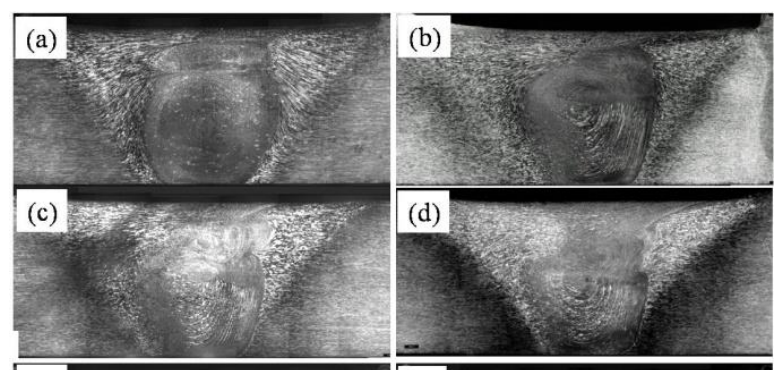

(e)
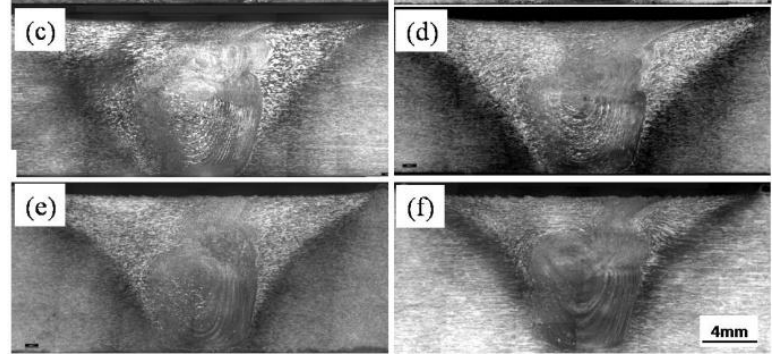

Figure 7.Weld macrostructures produced with (a) conical threaded tool at $40 \mathrm{~mm} / \mathrm{min}$ and (b-f) hybrid tool at $40,100,160,220,280 \mathrm{~mm} / \mathrm{min}$, respectively

At the weld travel speed of $280 \mathrm{~mm} / \mathrm{min}$ (Figure 7f), the hybrid tool produces a minimal width of the nugget zone. The increased travel speeds allowed by the use of the hybrid tool enhance the weld pitch 
ratio, which in turn reduces the widths of the nugget zone and TMAZ. These findings establish the efficacy of a hybrid tool in producing welds with uniform macrostructure at very high travel speeds.

\subsection{Microstructural Analysis}

The microstructures of the different zones of the weld made by the conical threaded tool pin are shown in Figure 8. The weld produces two onion rings formed in the nugget zone, one at the bottom and the other at the top. The onion ring formed at the bottom of the nugget zone is due to the material flow around the threaded tool pin during stirring so that the nugget looks like a pot. While the onion ring at the top has an elliptical shape that could be because the shoulder driven flow dominates the pin driven flow just below the shoulder. The nugget zones at the top, middle, and bottom (Figure $8 b-d$ ) possess a fine equiaxed grain structure that is formed due to the dynamic recrystallization that occurs during friction stirring. The grain size in the nugget zone reduces from $20 \mu \mathrm{m}$ at the top (Figure $8 \mathrm{~b}$ ) to $10 \mu \mathrm{m}$ at the bottom (Figure $8 \mathrm{~d}$ ), as shown in Figure 9. This variation in grain size could be due to the difference in the rate of plastic deformation and gradient in temperature experienced by the different zones during stir welding.

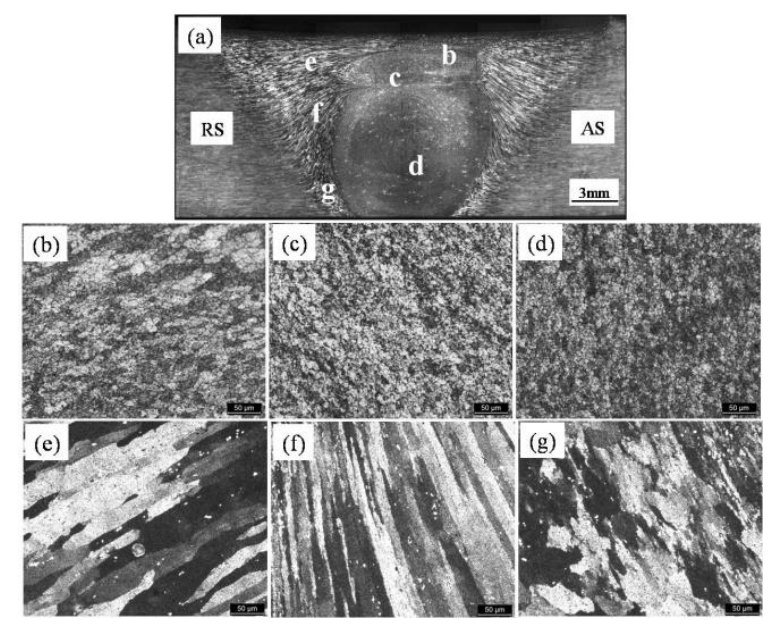

Figure 8 (a) Microstructures of weld produced with welding parameters $500 \mathrm{rpm}, 40 \mathrm{~mm} / \mathrm{min}$ using conical threaded tool. Stir zone at top (b), at middle (c), at bottom (d). TMAZ at top (e), at middle (f), at bottom (g).

The top of the nugget zone is exposed to a higher degree of heating and the larger centrifugal force due to the close contact with the tool shoulder, which further results in grain growth after dynamic recrystallization. The bottom of the nugget zone is in contact with the backing plate that acts as a heat sink. The bottom zone experiences shorter weld thermal cycles and lower peak temperatures, which slows the grain growth, resulting in smaller grain size at the bottom of nugget zone. These observations are in line with the findings of $\mathrm{Xu}$ et al. (2013). 

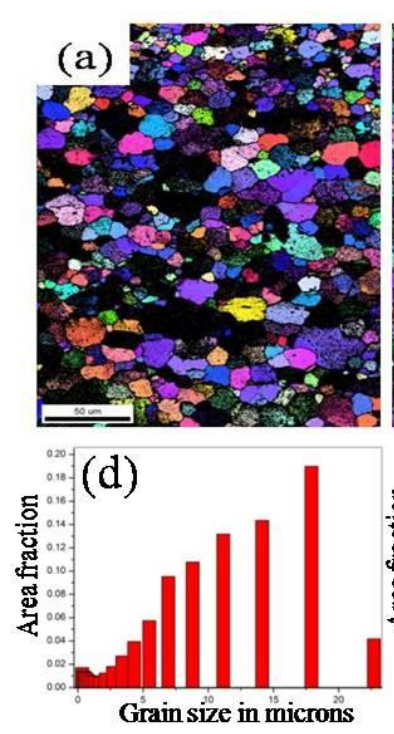
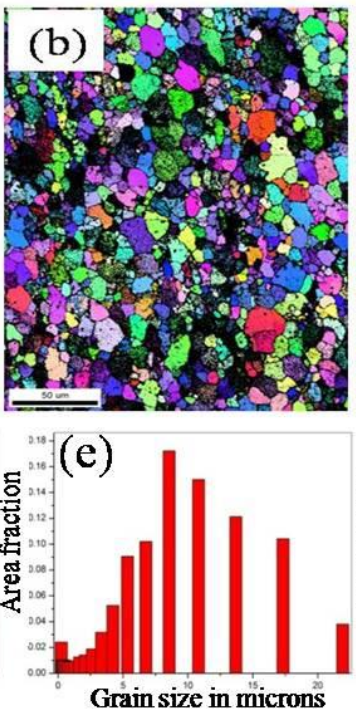
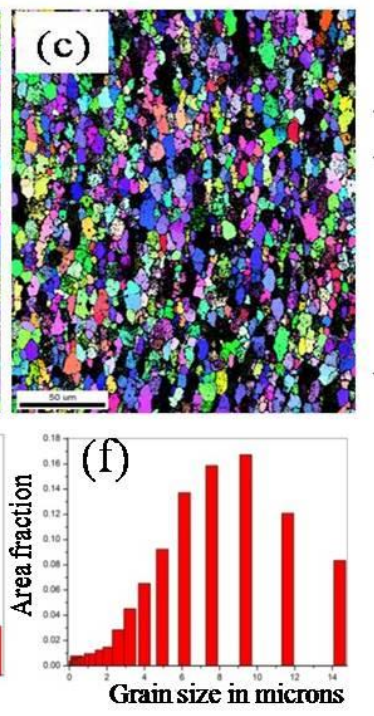

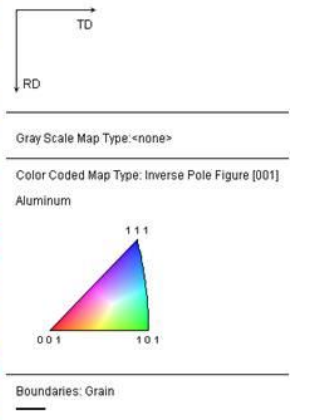

Boundaries: Grain

Figure 9. Electron back scattered diffraction images and corresponding column charts of grain size versus area fraction of nugget zone for conical threaded tool, top (a)\&(d), middle (b)\&(e), bottom (c)\&(f).

The TMAZ (Figure 8e-g) is a transition region between the nugget zone and the HAZ. The TMAZ experiences both stirring-assisted mechanical working and severe weld thermal cycles that result in a heavily deformed grain structure and associated grain growth. It is evident from Figure 8a that there exists a large variation in the width of the TMAZ throughout the thickness (from top to bottom). The TMAZ under shoulder (Figure 8e) is wider at the shoulder and induces extra heat and centrifugal force during stirring. The TMAZ is narrowest at the bottom of the nugget zone (Figure $8 \mathrm{~g}$ ) as the deformation and heat generated by the tool pin is comparatively smaller in this zone.

The microstructures of the weld made using the hybrid tool pin (at $500 \mathrm{rpm}$ and $280 \mathrm{~mm} / \mathrm{min}$ ) are shown in Figure 10. The macrostructure shows two distinct regions in the nugget zone. One region is close to the tool shoulder, which shows dynamically recrystallized grains in an elliptical shape (Figure 10a). The threaded portion touching the tool shoulder is responsible for the formation of this region. From close to the mid-thickness to the bottom of the nugget zone, striations are visible, indicating the severe plastic deformation caused by the triangular profile of the bottom part of tool pin. The TMAZ is smaller in welds made by the hybrid tool than those made by the conical threaded tool. A larger TMAZ is detected -from the top surface to mid-thickness of weld nugget - where the majority of stirring is caused due to the rotation and frictional heating created by the tool shoulder and the threaded portion of the hybrid tool pin. From mid-thickness to the bottom of the nugget zone, the TMAZ is almost negligible, which could be due to the localized shear deformation induced by the triangular edges of the hybrid tool pin. 


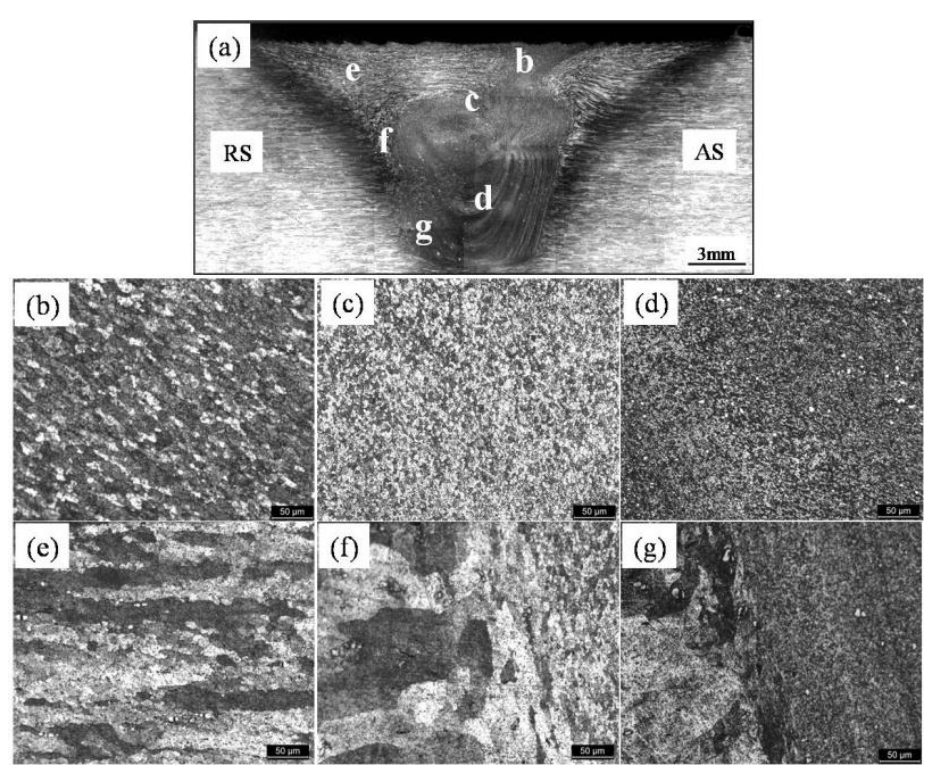

Figure10. (a) Microstructures of weld produced with welding parameters $500 \mathrm{rpm}, 280 \mathrm{~mm} / \mathrm{min}$ using hybrid tool pin. Stir zone at top (b), at middle (c), at bottom (d). TMAZ at top (e), at middle (f), at bottom (g).

The microstructure shown in Figure 10e depicts coarser and elongated grains in the TMAZ that are produced because of the heat imparted by the tool shoulder during rotation. The TMAZ region is formed due to the shoulder driven flow, and the width of this zone is relatively large. Figures $10 \mathrm{f}$ and $10 \mathrm{~g}$ show the microstructures of the interface between the TMAZ and the nugget zone at mid-thickness and at the bottom of the nugget zone respectively. In both of these zones, there is a drastic change in the grain size between the TMAZ and nugget zones. The TMAZ is comprised of elongated grains in the direction of metalworking caused by tool pin rotation and associated plastic deformation, which is similar to as indicated by $\mathrm{Xu}$ et al. $\left(2009^{\mathrm{b}}\right)$; whereas the grain size in the nugget zone is small, measuring just a few microns. The macrostructure depicts the reduced width of the nugget zone compared to that produced by a conical threaded tool pin. The increase in tool travel speed and weld pitch, thereby reducing the residence time of the tool at any point along the weld joint, is the reason for this reduction in nugget size. The grain size in the nugget zone is reduced from the top $(10 \mu \mathrm{m})$ to the bottom $(3 \mu \mathrm{m})$ (Figure 11). The grain size in the nugget zone is relatively small when using the hybrid tool (Figure 11) compared to the conical threaded tool (Figure 9). The variation in grain size and the corresponding electron backscattered diffraction images of the TMAZs of the welds made by conical threaded and hybrid tools are shown in Figure 12. 

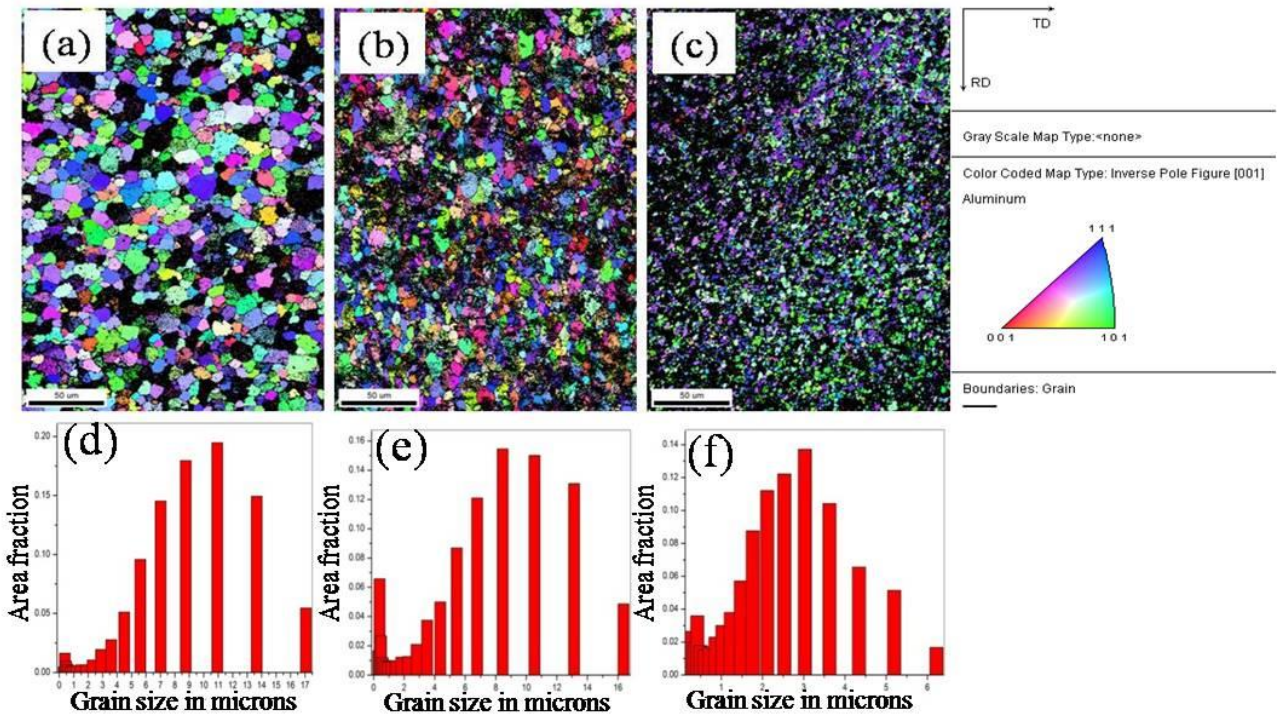

Figure 11. Electron back scattered diffraction images and corresponding column charts of grain size versus area fraction of the nugget zone for hybrid tool, top (a)\&(d), middle (b)\&(e), bottom (c)\&(f).
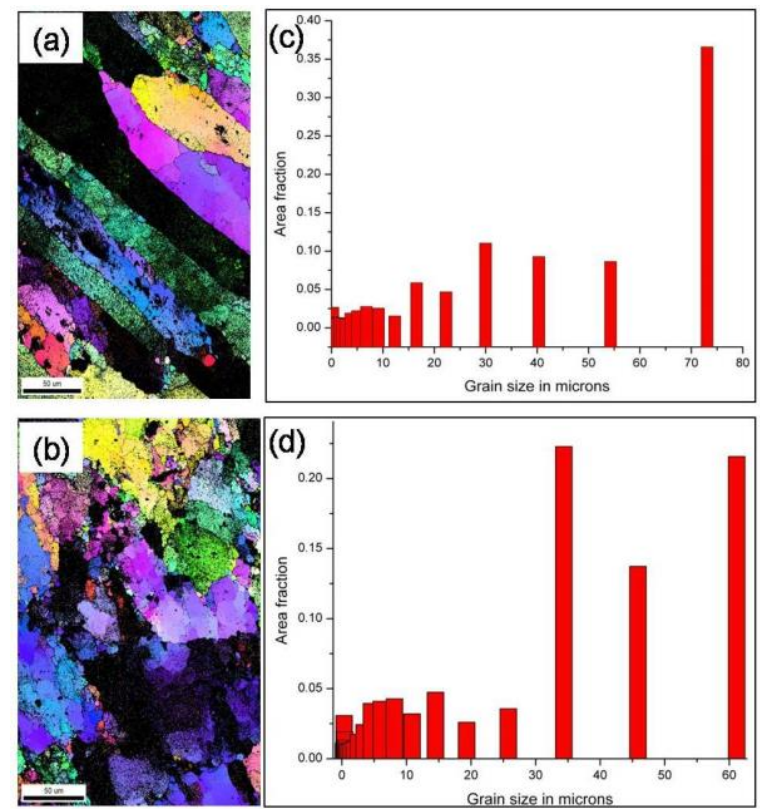

Figure 12. Electron back scattered diffraction images and corresponding column plots for grain size versus area fraction of TMAZs of welds made by conical threaded tool (a) \& (c), hybrid tool (b) \& (d).

The maximum grain size in the TMAZ of a hybrid tool produced weld was $60 \mu \mathrm{m}$ with an area fraction of 0.24 , while the same values for the weld made by the conical threaded tool were $72 \mu \mathrm{m}$ and 0.37 , respectively. It is evident from Figures 9, 11, and 12 that the grain size in all of the zones of the welds made by the hybrid tool is smaller than for those welds produced by the conical threaded tool. This 
can be attributed to the faster weld travel speeds and the resulting higher weld pitch possible with a hybrid tool compared to the conical threaded tool. Moreover, the grain size is reduced from top to bottom within the nugget zone for all of the welds made by either of the tools. The microstructural changes are associated with phase changes, as discussed next.

\subsection{Distribution of $\boldsymbol{\theta}$ - particles}

The optical microstructure of the as-received base material of the AA2219 aluminum alloy in the T6 condition is shown in Figure 13. The base material consists of typically elongated grains measuring approximately to 2 to $3 \mathrm{~mm}$ with $\theta\left(\mathrm{CuAl}_{2}\right)$ particles spread across the whole matrix. The precipitation sequence, as mentioned by Li and Schen (2011) in a supersaturated solid solution of theAA2219 aluminum alloy, is described in Equation 1:

$\alpha \rightarrow \alpha+$ GP zones $\rightarrow \alpha+\theta^{\prime \prime} \rightarrow \alpha+\theta^{\prime} \rightarrow \alpha+\theta$

where $\alpha$ is a solid solution of $\mathrm{Cu}$ in the $\mathrm{Al}$ matrix, and GP zones are Guinier-Preston zones.

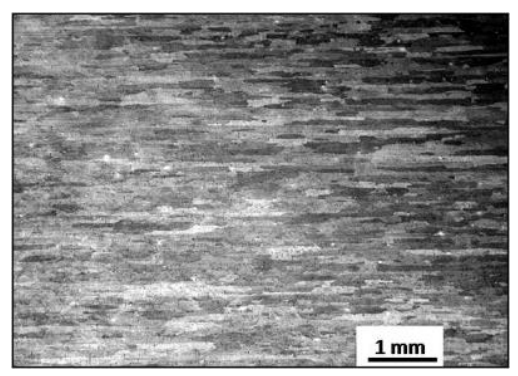

Figure13. Typical optical microstructure of AA2219 aluminum alloy base material

After precipitation-hardening or aging, the alloy attains a higher strength due to the impediment of dislocations by $\theta^{\prime \prime}$ and $\theta^{\prime}$ precipitates. The $\theta$-particle is anintermetallic compound $\left(\mathrm{CuAl}_{2}\right)$ thatremains incoherent to the $\alpha$-matrix. The distribution of $\theta$-particles $\left(\mathrm{CuAl}_{2}\right)$ across the nugget zone and the TMAZ of welds produced by the conical threaded and hybrid tools are shown in Figures 14 and 15, respectively. The chemical composition of the $\theta$-particles $\left(\mathrm{CuAl}_{2}\right)$ corresponding to the zone in Figure 14(d) was confirmed by EDAX data (Figure14e). 

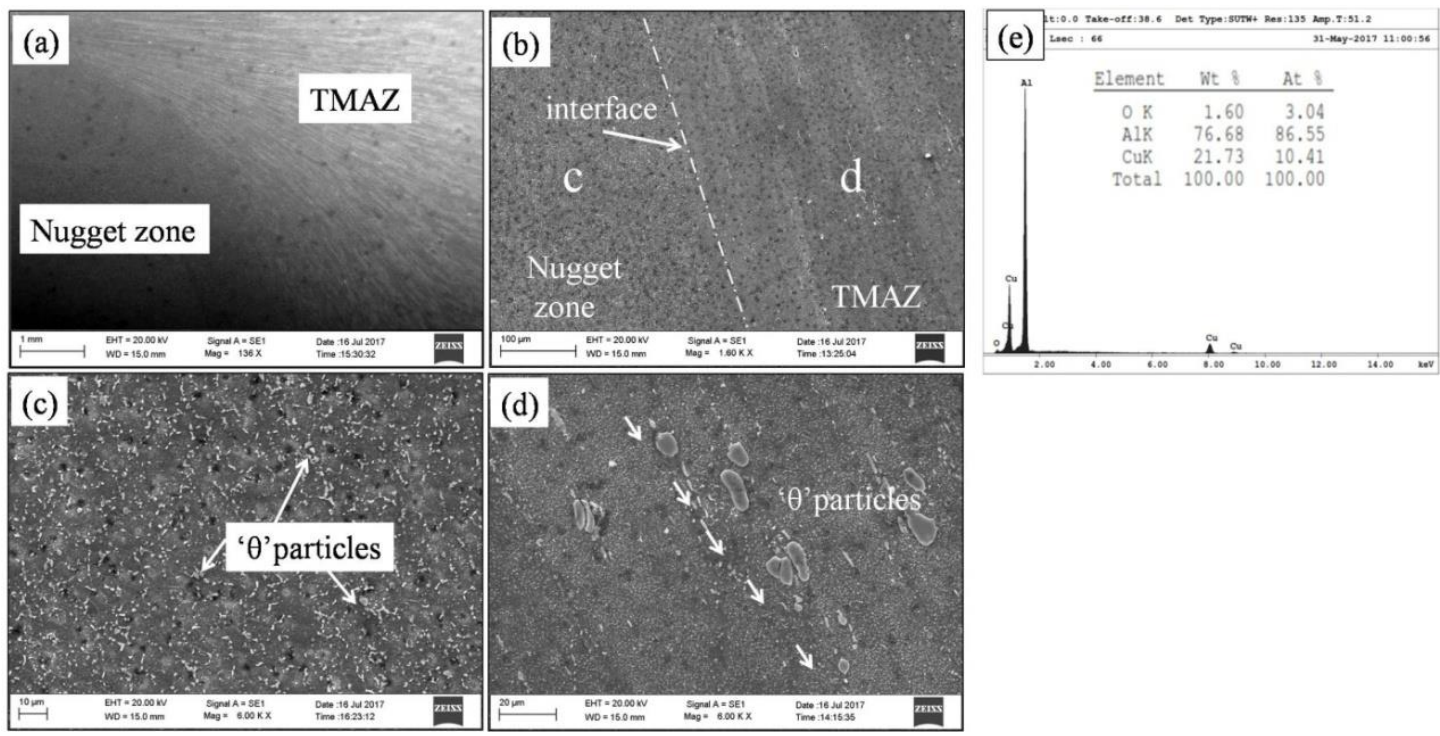

Figure14. Scanning electron micrographs of weld made by conical threaded tool (a) \& (b) interface between TMAZ and NZ at low and high magnifications respectively, (c) \& (d) zones marked in (b) at high magnification, arrows indicate direction of material flow in NZ, (e) EDAX results of $\theta$-particles shown in (d)
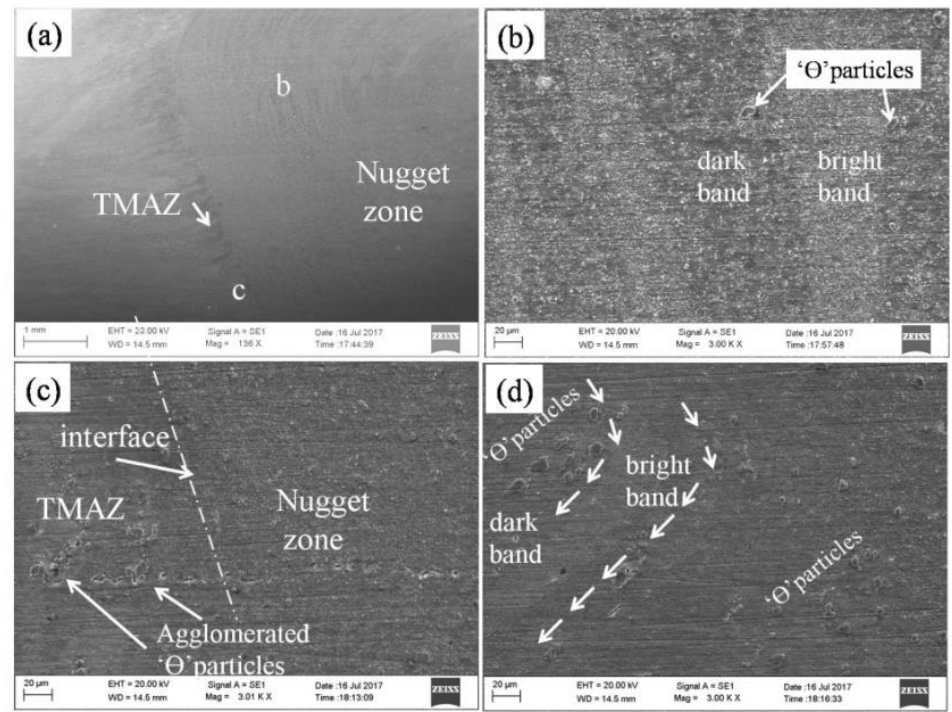

Figure15.Scanning electron micrographs of weld made by hybrid tool (a) interface between TMAZ and NZ at low magnification, (b) \& (c) zones marked in (a) at high magnification, (d) NZ close to interface on retreating side, arrows indicate direction of material flow in NZ.

For the nugget zone produced by the conical threaded tool, the size $(\sim 3 \mu \mathrm{m})$ and population of $\theta$ particles are much less, than the size $(\sim 10 \mu \mathrm{m})$ of particles in the nugget zone made by the hybrid tool. As 
the conical threaded tool traversed with a slow speed, the residence time of the tool at a particular location is high and the prior existing particles fragmented into tiny particles due to their interaction with the tool. Cao and Kou (2005) also reported that the $\theta$-particles defragmented and agglomerated in the nugget zone near the locations close to the pin surface. While the hybrid tool can traverse with high speed and the material is detached due to shear at the vertical edges of triangular portion, the fragmentation of $\theta$-particles within the nugget zone is limited, and the particles follow the material flow direction as indicated by arrows in Figure 15. Xu et al. $\left(2009^{b}\right)$ reported that the size of the $\theta$-particles in the nugget zone increased with increasing travel speed. The bands (as shown in Figure 15d) are noticed in the nugget zone of the hybrid tool where the dark bands are more populated with $\theta$-particles while the bright bands are observed to possess a lesser number of $\theta$-particles. A similar observation is reported by and Li and Schen (2011).

\subsection{Microhardness}

The comparative distribution of micro-hardness at a mid-thickness across the transverse cross section of weld joints produced with both conventional conical threaded tool (at $40 \mathrm{~mm} / \mathrm{min}$ ) and hybrid tool (at $280 \mathrm{~mm} / \mathrm{min}$ ), in an as-welded condition, is shown in Figure16. The hardness is influenced by the type of tool employed during the friction stir welding. The variation in hardness, in case of welds made by both the tools, clearly indicates the softening in the TMAZ and nugget zones due to the exposure to the severe heat input during welding. The hardness of the base material is measured as $139-145 \mathrm{Hv}$. Similar TMAZ softening was reported by Liu et al.(2011 ), Zhang et al. (2012), and Reddy et al. (2009).

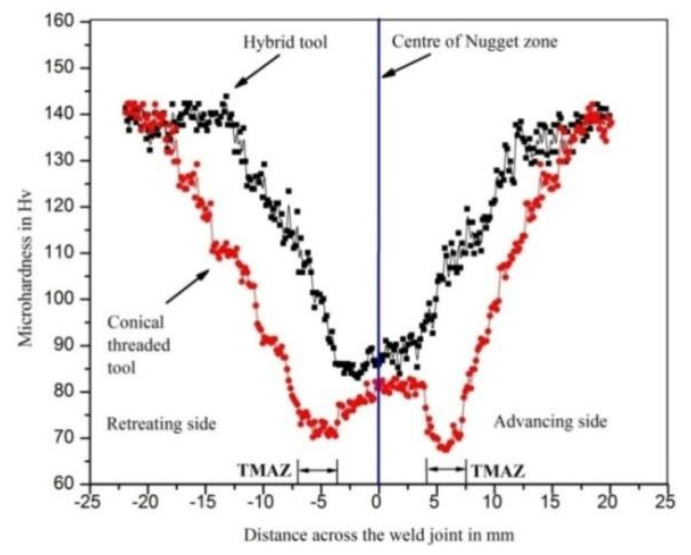

Figure16. Micro-hardness distribution in conventional conical threaded tool and hybrid tool

Relatively lower hardness values are obtained in all zones of the weld joint made by the conical threaded tool compared to those produced using the hybrid tool. This is due to the increase in hardness with decreasing grain size, which is consistent with the Hall-Petch relationship. The hardness in the nugget zone of the weld made by the conical threaded tool was $75-80 \mathrm{Hv}$, while that of the weld realized with 
the hybrid tool was 86-93 Hv. The lower hardness values corresponding to the weld of the conical threaded tool are attributed to the coarser grain size compared to that of weld made by the hybrid tool. The lowest hardness value (67Hv) was detected in the TMAZ of the weld with the conical threaded tool, and the width of the minimum hardness zone was approximately $5 \mathrm{~mm}$. The reduction in the hardness of TMAZ is attributed to the coarsening of precipitates $\left(\theta^{\prime}\right)$ due to the prolonged exposure to weld thermal cycles [also reported by Huijie et al. (2010) and Zhang et al. (2012)]; temperature beyond $200^{\circ} \mathrm{C}$ for more than 15s, as shown in Figure 5. In case of the weld produced with the hybrid tool, the minimum hardness is measured near the interface of the retreating side of the TMAZ and nugget zone, and the hardness increases while moving from the nugget line to the base metal. The width of the TMAZ is negligible in the weld joint produced by the hybrid tool because the peak temperature and exposure time are much less (Figure 5). The hybrid tool was capable of welding at high travels speed due to improved material flow in the nugget zone. This led to lowering heat input and peak temperatures in TMAZ.

\subsection{Tensile properties}

The tool pin profile and the welding parameters have a pronounced effect on the mechanical properties (Table 3) and fractured locations of friction stir weld joints (Figure 17).Typical engineering stress-strain plots are shown in Figure 18. The ultimate tensile strength and yield strengths of the weld made by the hybrid tool at $280 \mathrm{~mm} / \mathrm{min}$ speed were higher than for the weld made by the conical threaded tool. The tensile strengths of the welds made by both of the tools at a $40 \mathrm{~mm} / \mathrm{min}$ travel speed are almost equal, having a failure in the TMAZ, which further demonstrates that the travel speed and weld pitch have major impacts on the mechanical properties of the weld joint. The friction stir weld produced by the conical threaded tool fractured in the TMAZ, in the advancing side, and had a higher degree of softening due to the coarsening of precipitates, while the welds made by the hybrid tool fractured close to the nugget and the TMAZ interface near the retreating side, which was also reported by Ramanjaneyulu et al. (2013). The work of Chen et al. (2009) also reports tensile fracture in the TMAZ of the friction stir weld of theAA2219 alloy. TMAZ softening during welding is reduced considerably by using the hybrid tool. The grain size in the TMAZ of the hybrid tool-produced weld joint at $280 \mathrm{~mm} / \mathrm{min}$ is considerably smaller than that made by the conical threaded tool. The hardness distribution (Figure16) in the weld made by the hybrid tool at $280 \mathrm{~mm} / \mathrm{min}$ clearly indicates that the nugget zone interface at the retreating side has a lower hardness than the advancing side. It is found that the width of the TMAZ under the shoulder is wider on the retreating side than the advancing side, which might have initiated the fracture in the TMAZ under the hybrid tool shoulder, which might then have propagated to the nugget zone interface at the bottom. The reduced strength and percent elongation for the welds of the conical threaded tool are attributed to the presence of 
coarsened and agglomerated $\theta$-particles in the TMAZ. Figure 19 shows scanning electron micrographs indicating the presence of coarsened and cracked $\theta$-particles near the fracture surface of the weld made by the conical threaded tool. The presence of coarser $\theta$-particles reduces the strength due to partial depletion of the major alloying element $(\mathrm{Cu})$ from the surrounding $\alpha$-matrix ( $\mathrm{Li}$ and Schen, 2011).The presence of a high population of $\theta$-particles in the TMA, which are incoherent to the matrix, leads to a inferior percent elongation/ductility for the welds made by the conical threaded tool compared to those made by the hybrid tool (Figure19).

Table 3. Comparison of tensile properties of FSW joints made by both the tools

\begin{tabular}{|c|c|c|c|c|c|c|}
\hline $\begin{array}{c}\text { Tool pin } \\
\text { profile }\end{array}$ & $\begin{array}{c}\text { Rotation } \\
\text { speed }(\mathrm{rpm})\end{array}$ & $\begin{array}{c}\text { Travel speed } \\
(\mathrm{mm} / \mathrm{min})\end{array}$ & $\begin{array}{c}\text { UTS } \\
(\mathrm{MPa})\end{array}$ & $\begin{array}{c}\text { YS } \\
(\mathrm{MPa})\end{array}$ & $\begin{array}{c}\text { Elongation } \\
(\%)\end{array}$ & Failure Location \\
\hline Conventional & 500 & 40 & $295^{ \pm 2.2}$ & $144^{ \pm 4.3}$ & $9.1^{ \pm 0.6}$ & TMAZ - advancing side \\
\hline Hybrid & 500 & 40 & $294^{ \pm 0.9}$ & $145^{ \pm 1.3}$ & $7.4^{ \pm 0.4}$ & TMAZ - retreating side \\
\hline Hybrid & 500 & 280 & $335^{ \pm 10}$ & $185^{ \pm 5}$ & $5.3^{ \pm 0.25}$ & TMAZ \& NZ Interface - retreating side \\
\hline
\end{tabular}
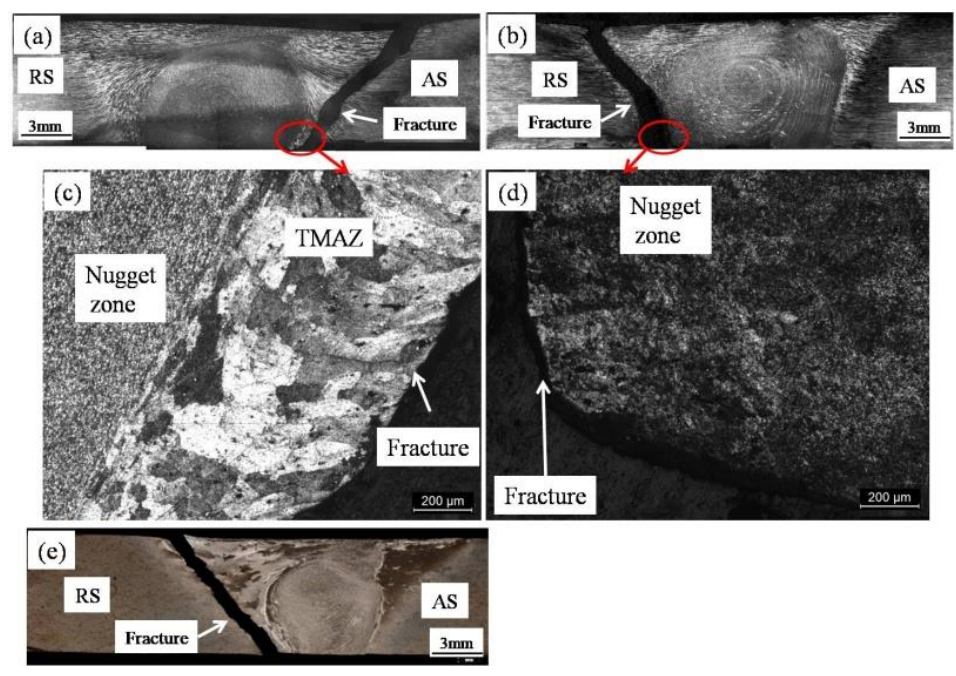

Figure 17. Macrographs of Fractured tensile test specimens of weld produced by (a) conical threaded tool at 500rpm and $40 \mathrm{~mm} / \mathrm{min}$, (b) hybrid tool at $500 \mathrm{rpm}$ and $280 \mathrm{~mm} / \mathrm{min}$, (c) \& (d) high magnification microstructure at fracture shown in (a) \& (b) respectively (e) hybrid tool at 500rpm and $40 \mathrm{~mm} / \mathrm{min}$ 


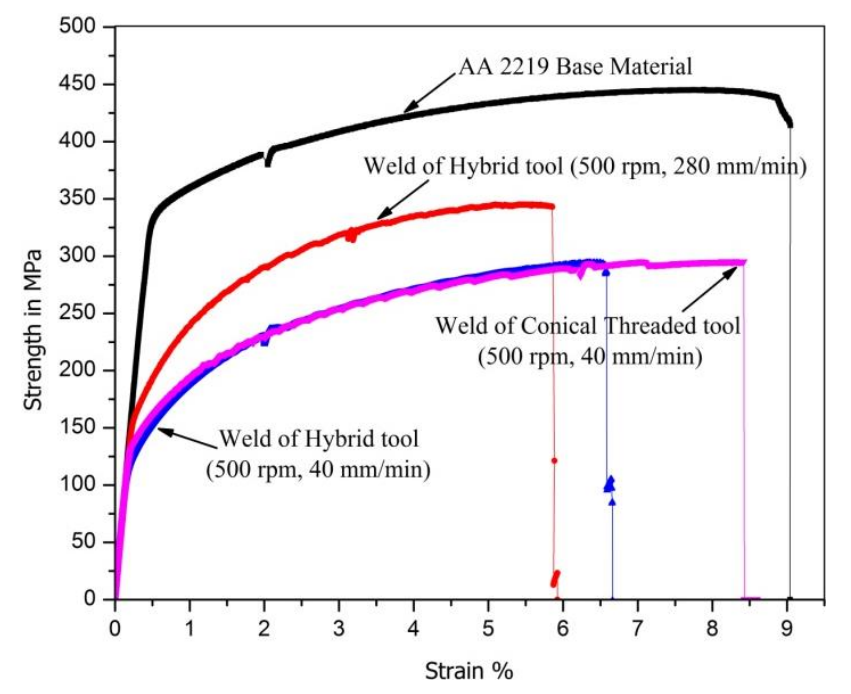

Figure 18. Typical Stress-strain plots of base material and welds

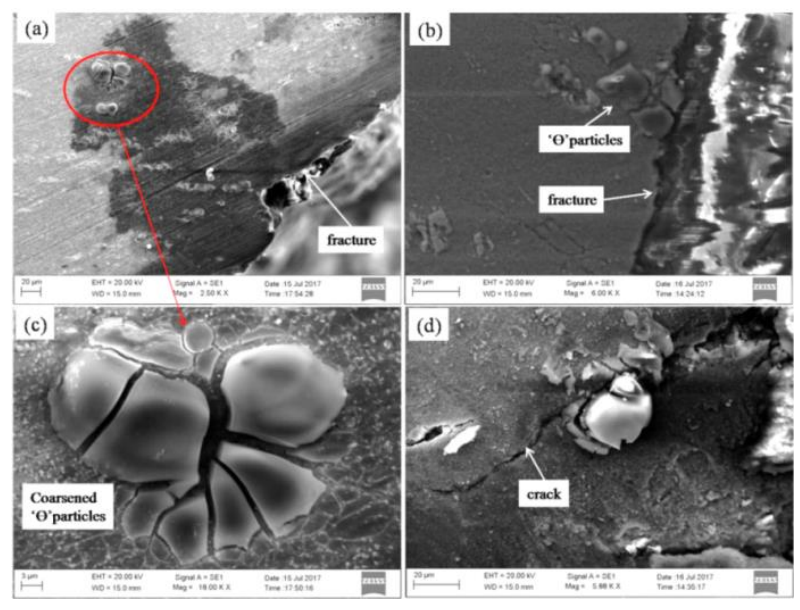

Figure 19. Scanning electron micrographs showing the presence of coarsened and cracked $\theta$ particles near the fracture surface of weld made by the conical threaded tool.

\subsection{Fractography}

The scanning electron microscope (SEM) images of the fractured surfaces of the tensile test specimens made using the conical threaded tool and hybrid tool are shown in Figures 20 and 21, respectively. More $\theta$-particles with larger size can be seen in the fractographs that belong to the conical threaded tool (Figures $20 \mathrm{~b}$ and d) compared to those made by the hybrid tool (Figures $21 \mathrm{~b}$ and d). The $\theta$-particles were embedded between the ductile dimples, which is similar to the observations of $\mathrm{Xu}$ et al. $\left(2009^{\mathrm{b}}, 2013\right)$. Under the tensile loading conditions, the $\theta$-particles are sheared in cleavage fracture mode, while the surrounding matrix deforms sufficiently, as evidenced by the dimpled features. As the $\theta$-particles are incoherent to the matrix, they do not deform in line with the surrounding matrix. The presence of a greater population of larger-sized and cracked $\theta$-particles in the TMAZ of the weld made by the conical threaded tool results in 
reduced strength and a lesser percent elongation compared to welds produced with the hybrid tool. Cao and Kou (2005) and Li and Schen (2011) reported similar observations in friction stir welds of AA2219 aluminum alloy.

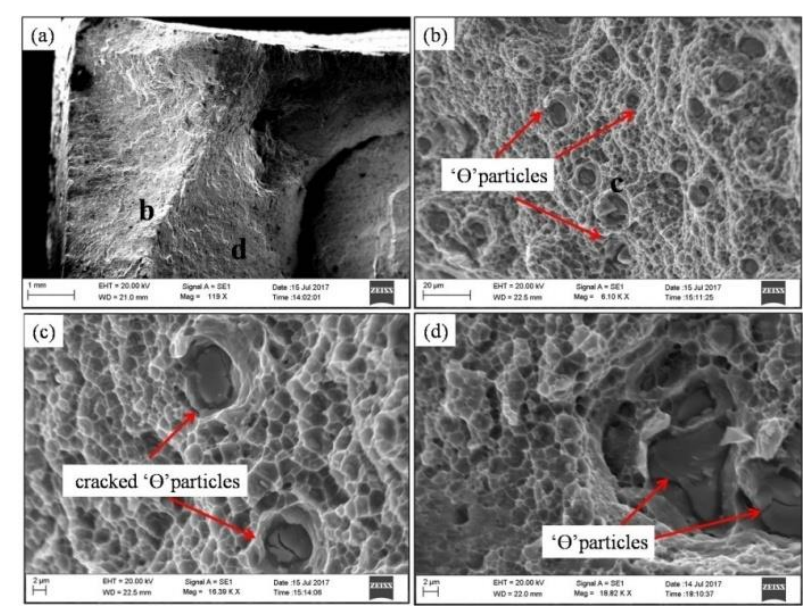

Figure 20. SEM images of fractured surface of tensile test specimen of weld made by conical threaded tool at 500rpm and 40mm/min (a) whole fracture surface at low magnification (b), (c) and (d) high magnification fractographs of zones as indicated in (a) \&(b)

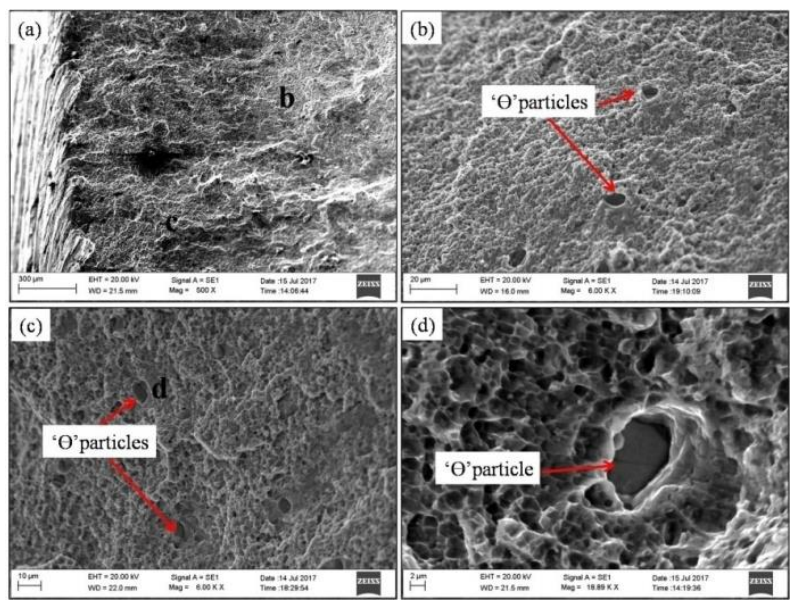

Figure21. SEM images of a fractured surface of tensile test specimen of weld made by hybrid tool at 500 rpm and $280 \mathrm{~mm} / \mathrm{min}$ (a) whole fracture surface at low magnification (b), (c) \& (d) high magnification fractographs of zones as indicated in (a) \& (c), respectively.

\subsection{Identifying the mechanism responsible for the improved efficacy of the hybrid tool}

A schematic of the FSW process parameters, resulting forces, and torque acting on the tool is given in Figure 22. At any moment in time during the FSW process, three directional forces and one unidirectional torque act on the tool because of plasticized material flow around the tool pin. As the tool traverses in the 
welding direction, it encounters the un-deformed base material near the leading edge, which produces a compressive force that acts on the tool pin. The plasticized base material travels around the tool pin from the advancing side to the retreating side and is forged by the tilted tool shoulder at the back of the tool. The resultant force $\left(\mathrm{F}_{\mathrm{x}}\right)$ acting on the tool pin in the direction of welding is the combined effect of undeformed base material at the leading edge and forged plasticized material at the rear of the tool. Similarly, the resultant force acting on the tool pin in the transverse direction to the welding direction due to the movement of plasticized weld material is designated as $F_{y}$. The force in the direction of the tool axis due to the rotation and forging of plasticized material $\left(\mathrm{F}_{\mathrm{z}}\right)$ and torque $(\mathrm{T})$ is also exerted on the tool about the tool axis. All of the forces and torque are measured with the inbuilt force monitoring system in the FSW machine. Average torque, forces acting on the tool, and heat generated during the welding process were calculated and are given in Table 4.

The heat input was calculated using Equation 2 [Pew et al., 2007]:

Heat input in $\mathrm{J} / \mathrm{mm}, Q=\eta \frac{2 \Pi N T}{v}$

where $\mathrm{T}=$ torque in $\mathrm{N}-\mathrm{m}, \mathrm{N}=$ tool rotation speed in $\mathrm{rpm}, v=$ travel speed in $\mathrm{mm} / \mathrm{min}$, and $\eta=$ thermal efficiency of the FSW process.

Thermal efficiency $(\eta)$ may be considered as 0.9 for the case of friction stir welding of aluminum alloys using an FSW tool made of steel (Dickerson et al., 2003).

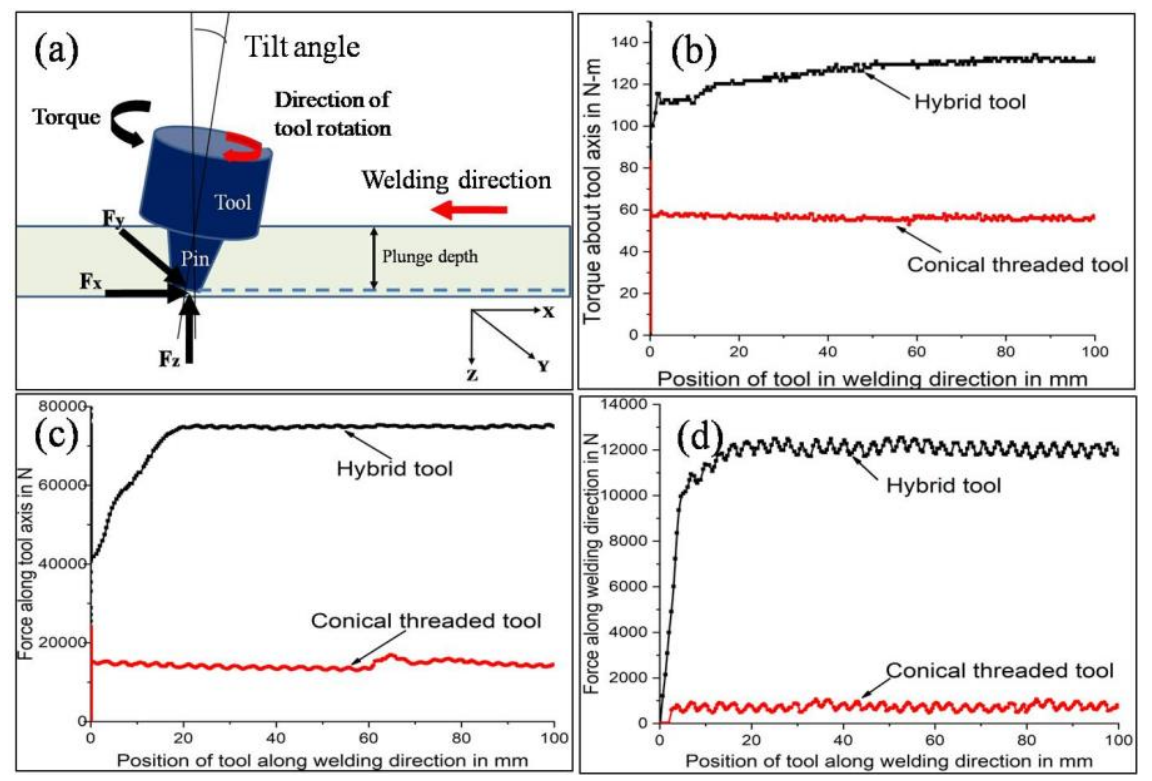

Figure 22. (a) A schematic of FSW process, resulting forces, and torque acting on the tool (b) torque about tool axis, (c) force along tool axis, (d) force along welding direction observed, while welding with conical threaded tool at $500 \mathrm{rpm} \& 40 \mathrm{~mm} / \mathrm{min}$ and hybrid tool at $500 \mathrm{rpm} \&$ $280 \mathrm{~mm} / \mathrm{min}$ 
Table 4. Average torque, forces acting on the tool and heat input during the welding process

\begin{tabular}{|l|l|l|l|l|l|}
\hline S.No & $\begin{array}{l}\text { Type of tool \& welding } \\
\text { parameters }\end{array}$ & $\begin{array}{l}\text { Torque } \\
(\mathrm{N}-\mathrm{m})\end{array}$ & $\begin{array}{l}\text { Force along tool } \\
\text { axis }(\mathrm{Fz}) \text { in } \mathrm{N}\end{array}$ & $\begin{array}{l}\text { Force along X-axis } \\
(\mathrm{Fx}) \text { in N }\end{array}$ & $\begin{array}{l}\text { Heat input } \\
(\mathrm{kJ} / \mathrm{mm})\end{array}$ \\
\hline 1 & $\begin{array}{l}\text { Conical threaded tool } \\
(500 \mathrm{rpm}-40 \mathrm{~mm} / \mathrm{min})\end{array}$ & 60 & 15201 & 980 & 4.24 \\
\hline 2 & $\begin{array}{l}\text { Hybrid tool (500rpm- } \\
280 \mathrm{~mm} / \mathrm{min})\end{array}$ & 130 & 78835 & 12116 & 1.31 \\
\hline
\end{tabular}

Figure 22b and c show the comparative variation of measured torque, for both tools, different forces act on the tools with respect to the position of the tool in the welding direction. It is evident from Figure $22 \mathrm{c}$ and $\mathrm{d}$ that the steady-state regime is reached after welding a length of $20 \mathrm{~mm}$. All of the forces and torque acting on the hybrid tool are greater than those acting on the conical threaded tool. The effective heat input introduced by the hybrid tool during the welding process is less than that of the conical threaded tool. The hybrid tool produces higher rate of heat generation than the conventional tool which increases material flow in the nugget zone and a higher weld pitch. This demonstrates the greater efficacy of the hybrid tool in transferring deformation forces to the workpiece material relative to the conical threaded tool. The conventional conical threaded tool cannot withstand a travel speed of more than $40 \mathrm{~mm} / \mathrm{min}$ (i.e., it cannot transfer the load to the workpiece and breaks). The hybrid tool could reach a speed of up to $280 \mathrm{~mm} / \mathrm{min}$. The design of hybrid tool facilitates an effective utilization of deformation heat (i.e., the TMAZ is smaller, and the joint efficiency is higher, as discussed earlier).

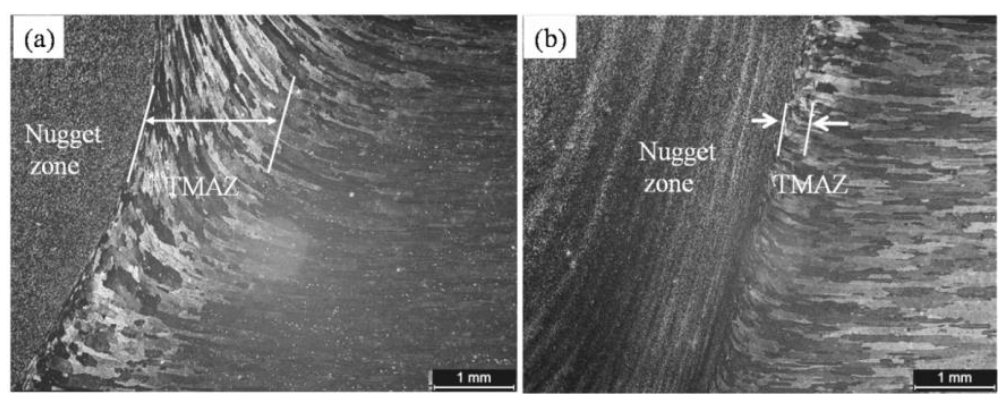

Figure 23. Width of TMAZ produced by (a) conical threaded tool at $40 \mathrm{~mm} / \mathrm{min}(\mathrm{b})$ hybrid tool at $280 \mathrm{~mm} / \mathrm{min}$.

In case of polygonal tool pin profiles, the ratio of pin volume (static volume) to the swept volume (dynamic volume), as reported by Ramanjaneyulu et al. (2014) and Elangovan and Balasubramanian (2008), determines the extent of plastic deformation in the base material around the tool pin. The same ratio influences the rate of heat generation through plastic deformation. The heat generated in case of a conical threaded pin is exclusively through friction between the tool and adjacent base material so that it 
takes a considerably longer time for the generation of heat, as well as the conduction of heat to the undeformed or the unaffected base material. The TMAZ, which is sandwiched between the HAZ and the nugget zone, remains for relatively long durations and experiences higher peak temperatures when using the conventional tool than the hybrid tool. Because of this, as shown in Figure 23, the TMAZ produced by the conical threaded tool is wider than that of the hybrid tool. Therefore, the hybrid tool experiences and is able to withstand higher levels of torque and forces than the conical threaded tool. In the case of the weld produced by the conical threaded tool, the material flow is in line with the earlier reported analysis and material flow models reported by Elangovan et al. (2008), Ramanjaneyulu et al. (2014), and Mehta et al. (2015). As the tool rotates and traverses along the welding seam, a newly undeformed material first comes into contact with the tool shoulder at the advancing side and flows around the tool pin towards the bottom of the retreating side of the joint. After reaching the bottom of the joint, the velocity of the material flow does not reach zero, but the material backflows from the bottom surface of the joint supported by the backup plate. In this manner, the material flow currents encircle the axis of the weld joint, and onion rings are formed as the tool traverses ahead. In case of the hybrid tool, the material starts moving from the advancing side under the shoulder and moves downwards across the tool pin towards the retreating side.

The material flows downwards until the end of the threaded portion of the tool and is deformed rapidly by the flat edges of the triangular part of the tool due to the rapid rate of heat generation. The threaded portion of the hybrid tool (just below the tool shoulder) results in an onion ring. The shoulderdriven material flow currents influence this onion ring formation. As a result, elliptically shaped onion rings are formed on top of the nugget zone. The triangular portion of the tool leads to the displacement of material by detachment near the sharp edges of the tool, and finally, the detached material undergoes relative lesser deformation and consolidates at the back of the tool. Due to this phenomenon, as well as the high tool travel speed, a vertical banded structure (Figure 23) can be detected in the part of the nugget zone formed by the triangular tool pin profile. This combined macrostructure, depicting both elliptical onion rings and vertical banded structure, is clearly visible in Figure 10a. Ultimately, it is the tool pin profile, in combination with FSW process parameters, which affects the heat generation and mass transport of the process. Thermal and mass transport is one of the essential aspects that govern the quality, final microstructures and mechanical properties of weld.

\section{Conclusions}

1. A hybrid tool pin geometry is employed for welding thick AA 2219-T6 aluminum alloy to control material flow, the rate of heat generation and, thereby, to maximize the travel speed and weld pitch. The 
operating window of the friction stir welding parameters is widened with the use of a hybrid tool for the tested thickness of AA2219-T6 aluminum alloy.

2. By microstructural examination, for both of the tested tools, varied grain sizes are detected in the nugget zones throughout the thickness of the weld joints. Coarser grain size was detected in the part of the nugget zone close to the shoulder, while the bottom section had a smaller grain size.

3. Compared to the welds produced by the hybrid tool, the TMAZ of welds made by the conical threaded tool are coarser and have deformed grains with the presence of large and agglomerated $\theta$ particles. The increased travel speed employed while welding with the hybrid tool results in limited defragmentation of the $\theta$-particles in the nugget zone.

4. The welds made by the conical threaded tool have inferior mechanical properties than welds made by the hybrid tool. This is because of coarsening or dissolution of $\theta^{\prime}$-precipitates and coarsening or agglomeration of $\theta$-particles in TMAZ, which result from prevailing higher peak temperatures and prolonged exposure times at high temperature.

5. The specially designed hybrid tool pin profile has potential to produce friction stir welds with enhanced mechanical properties relative to conventional conical threaded tools. Welding with higher travel speeds by using a hybrid tool results in superior mechanical properties that are the cumulative effect of lower peak temperatures and faster cooling rates in the TMAZ.

\section{Acknowledgements}

The financial support from the Defence Research and Development Organization is greatly acknowledged. The authors are thankful to Shri MSR Prasad, Director of the Defence Research and Development Laboratory (DRDL) and the Director of the Defence Metallurgical Research Laboratory (DMRL) for continued encouragement and for providing permission to publish this work.

\section{References}

1. Avettand, F.M., Taillard, M., 2015. Heterogeneity of the nugget microstructure in a thick $2050 \mathrm{Al}$ friction stirred weld. Metallurgical and Materials Transactions A, 46(1), 300-314.

2. Cao, G., Kou, S., 2005. Friction stir welding of 2219 aluminium: Behaviour of $\theta\left(\mathrm{Al}_{2} \mathrm{Cu}\right)$ particles. The Welding Journal, 1s-8s.

3. Chen, C., Feng, J.C., Liu, H.J., 2009. Precipitate evolution in friction stir welding of 2219-T6 aluminium alloys. Materials Characterization, 60, 476-481.

4. De, P.S., Mishra, R.S., 2011. Friction stir welding of precipitation strengthened aluminium alloys: Scope and challenges. Science and Technology of Welding and Joining, 16(4), 343-347. 
5. Dickerson, T., Qing-yu S., Shercliff, H.R., 2003. Heat flow into friction stir welding tools. Proceedings of 4th International Symposium on Friction Stir Welding. Park City, Utah, USA, 14-16 May 2003.

6. Elangovan, K., Balasubramanian, V., 2008. Influence of tool pin profile and welding speed on the formation of friction stir processing zone in AA2219 aluminium alloy. Journal of Material Processing Technology, 20, 163-175.

7. Huijie, L., Zhang, H., Huang, Y., Lei, Y.U., 2010. Mechanical properties of underwater friction stir welded 2219 aluminium alloy. Transactions of Non-ferrous Metals Society of China, 20, 1387-1391.

8. Li, B., Schen, Y., 2011. The investigation of abnormal particle coarsening phenomena in friction stir repair weld of AA2219-T6 aluminium alloy. Materials and Design, 32, 3796-3802.

9. Li, J.Q., Liu, H.J., 2013. Effects of tool rotation speed on microstructures and mechanical properties of AA2219-T6 welded by the external non-rotational shoulder assisted friction stir welding. Materials and Design, 43, 299-306.

10. Liu, H.J., Zhang, H.J., Yu, L., 2011 ${ }^{\mathrm{a}}$. Effect of welding speed on microstructures and mechanical properties of underwater friction stir welded 2219 aluminium alloy. Materials and Design, 32, 1548 $-1553$.

11. Liu, H.J., Zhang, H.J., Yu, L., 2011 ${ }^{\mathrm{b}}$. Homogeneity of mechanical properties of underwater friction stir welded 2219-T6 aluminium alloy. Journal of Materials Engineering and Performance, 20(8), 1419-1422.

12. Mehta, M., Reddy, G.M., Rao, A.V., De, A., 2015. Numerical modeling of friction stir welding using the tools with polygonal pins. Defence Technology, 11, 229-236.

13. Perrett, J.G., Martin, J., Threadgill, P.L., Ahmed, M.M.Z., 2007. Recent developments in friction stir welding of thick section aluminium alloys. Proceedings of $6^{\text {th }}$ World Congress, Aluminium Two Thousand, Florence, Italy, 13 - 17 March 2007.

14. Pew, J.W., Nelson, T.W., Sorensen, C.D., 2007. Torque based weld power model for friction stir welding. Science and Technology of Welding and Joining, 12(4), 341-347.

15. Ramanjaneyulu, K., Madhusudhan Reddy, G., Rao, A.V., Markandeya, R., 2013. Structure-property correlation of AA2014 friction stir welds: Role of tool pin profile. Journal of Materials Engineering and Performance, 22(8), 2224-2240.

16. Ramanjaneyulu, K., Reddy, G.M., Rao, A.V., 2014. Role of Tool Shoulder Diameter in Friction Stir Welding : An Analysis of the Temperature and Plastic Deformation of AA 2014 Aluminium Alloy. Transactions of the Indian Institute of Metals, 67(5), 769-780. 
17. Rao, S.R.K., Madhusudhan Reddy, G., Rao, K.S., Rao, P.S., Kamaraj, M., Rao, K.P., 2004. Gas tungsten arc welded AA2219 alloy using scandium containing fillers-mechanical and corrosion behavior. Transactions of Indian Institute of Metals, 57(5), 451-459.

18. Reddy, G.M, Mastanaiah, P., Prasad, K.S., Mohandas, T., 2009. Microstructure and mechanical property correlations in AA 6061 aluminium alloy friction stir welds. Transactions of Indian Institute of Metals, 62(1), 49-58.

19. Upadhyay, P., Renolds, A., 2014. Effect of backing plate thermal property on friction stir welding of 25mm thick AA6061. Metallurgical and Materials Transactions A, 45(4), 2091-2100.

20. Xu, W., Jinhe, L., Guohong, L., Chunlin, D., 2009a . Temperature evolution, microstructure and mechanical properties of friction stir welded thick 2219-O aluminium alloy joints. Materials and Design, 30, 1886-1893.

21. Xu, W., Jinhe, L., Zhu, H., Li, F., 2013. Influence of welding parameters and tool pin profile on microstructure and mechanical properties along the thickness in a friction stir welded aluminium alloy. Materials and Design, 47, 599-606.

22. Xu, W., Jinhe, L., Guohong, L., Chunlin, D., 2009 ${ }^{\mathrm{b}}$. Microstructure and mechanical properties of friction stir welded joints in 2219-T6 aluminium alloy. Materials and Design, 30, 3460-3467.

23. Zhang, H.J., Liu, H.J, Yu, L., 2012. Effect of water cooling on the performance of friction stir welding heat affected zone. Journal of Materials Engineering and Performance, 21, 1182-1187, DOI: $10.1007 / \mathrm{s} 11665-011-0060-8$.

24. Zhang, H.J., Liu, H.J., Yu, L., 2011. Microstructure and mechanical properties as a function of rotation speed in underwater friction stir welded aluminium alloys. Materials and Design, 32, 44024407. 